\title{
CAMBIOS EN EL HÁBITAT HUMANO $Y$ SUS EFECTOS EN LA FAMILIA
}

Patricio de la Puente $\mathrm{L}$.

Se considera que un hábitat es el espacio que habita un ser vivo siendo, por tanto, el hábitat humano el lugar en que una persona o un grupo de personas reside o está asentada. vive.

La noción de hábitat implica la idea permanencia en un ámbito físico en que se

Por muchos siglos el hábitat humano no tuvo esta característica, sino que fue más bien precario y temporal. Sólo cuando el hombre comenzó a desarrollar actividades agrícolas se asentó en un territorio, por lo general, en valles fértiles, cultivando la tierra y ligándose permanentemente al suelo.

Sólo en el siglo xix se puede sostener que, en términos significativos, cambió el tipo de asentamiento humano desde uno eminentemente disperso hacia otro que tendió a la concentración de la población en el espacio, proceso éste impulsado por la revolución industrial. La industrialización implicó, pues, una relocalización paulatina de los grupos humanos en determinados centros: las modernas urbes.

Este proceso de urbanización demoró por cierto varias generaciones. Asi, se estima que el paso de un diez a treinta por ciento de "población urbana" demoró unos 80 años en Inglaterra, 16 años en Estados Unidos, 48 años en Alemania; 36 años en Japón.

Durante el presente siglo el ritmo de la urbanización en el mundo se ha incrementado, especialmente por la contribución de los países del Tercer Mundo y entre ellos, en particular, por el de los países latinoamericanos. La velocidad de la urbanización de éstos ha sido superior al doble al que aconteció en la centuria anterior en las naciones hoy industrializadas. Según los Censos de Población, uno de cada cuatro latinoamericanos residia en un asentamiento de más de 20.000 habitantes en 1950, uno de cada tres se encontraba en tal situación diez años después; en 1980, ya más de la mitad se radica en hábitat urbanos. 
Estos porcentajes promedios y agregados encubren sin embargo, grandes diferencias. En efecto, de los paises del Cono Sur de América Latina-Chile, Argentina, Uruguay- y Venezuela ya hacia 1950 aproximadamente el $45 \%$ de su población era clasificada como urbana, en tanto en la actualidad casi el $85 \%$ de ella tiene esta característica. En otros, como en Guyana, Jamaica, Haití, Honduras, Guatemala y El Salvador, la población urbana representa apenas entre el 20 y 40 por ciento de la población total en nuestros días.

Esta "urbanización explosiva" ha traído, entre otras consecuencias, una expansión territorial muy fuerte en las ciudades de la Región, provocando una pérdida de tierras que otrora eran aptas para su cultivo, fuertes alzas en los costos de urbanización de terrenos cada vez más periféricos y un consiguiente incremento en los tiempos de los desplazamientos que el habitante debe efectuar casi cotidianamente, entre su residencia y su lugar de trabajo.

Por otra parte, las ciudades latinoamericanas se han extendido en forma caóti$c a$, tornándose en mosaicos urbanos incoherentes en que coexisten edificios coloniales y grandes rascacielos; modernos "shopping-centers" y mercados tradicionales emplazados en cualquier intersticio apropiado; vetustas casas de adobe y bloques de departamentos construidos de acero y hormigón con fachadas de vidrios polarizados; poblaciones populares y exclusivos condominios privados; callejuelas sin pavimentar y vias elevadas para el automóvil; vetustos vehículos de locomoción colectiva y ferrocarriles metropolitanos computarizados.

Desde el punto de vista de los estilos arquitectónicos, subsisten y a veces superponen construcciones propias de los más diversos modelos y formas culturales foráneos que no han respondido, por tanto, a una concepción propia que exprese la identidad histórica de las naciones de la Región.

Como producto de estos procesos, la ciudad latinoamericana se ha desdibujado y perdido sus raíces, tornándose intrincada, laberíntica y poco legible o comprensible para sus habitantes, con lo cual éstos difícilmente logran una imagen unificada de ella. Más aún, si se trata de ciudades muy extendidas, como es el caso de Santiago, lo más probable es que un hombre común recorra y conozca sólo algunos pedazos o sectores, generalmente aquellos relacionados con sus viajes entre su domicilio y el trabajo.

Las caracteristicas brevemente reseñadas en los párrafos anteriores es probable que incidan en el desarrollo de ciertos comportamientos. Así, la identificación con un hábitat tan heterogéneo y dinámico como el prevaleciente en la ciudad, puede verse seriamente dificultado y los vínculos de arraigo con el lugar en que se vive pueden tornarse desfavorecidos. Si esto es así no debiera sorprendernos la falta de cuidado que es frecuente observar en la conservación de elementos y espacios urbanos públicos o semipúblicos: por ejemplo, los prados de las áreas verdes, los árboles de las calles, las señalizaciones y todo tipo de ornamentación urbana, las fachadas de los edificios, etc. 
Si no existe un compromiso en la población por la ciudad y en definitiva no la considera "su" ciudad, la tendencia a colaborar y participar en actividades colectivas encaminadas a mejorar su calidad será escasa. Estudios efectuados al respecto en diversos sectores de Santiago han revelado que la opinión generalizada es que la solución de casi cualquier problema de la ciudad es de responsabilidad de los gobiernos, las municipalidades o de reparticiones públicas específicas. El ciudadano común, al parecer, no se siente responsable por el deterioro del ambiente urbano $y$, menos aún, protagonista de acciones tendientes a su mejoramiento, prevaleciendo en cambio actitudes de apatía e indiferencia.

Diversos autores han destacado el fenómeno paradójico con que el "citadino" se encuentra, en términos que si bien en la ciudad existen las máximas posibilidades para la interacción social y, en la práctica, los contactos interpersonales en un medio tan densamente poblado son casi constantes, la calidad de ellos tienden a ser inferiores en comparación a aquellos que se observan en medios rurales. Es familiar que en los grandes centros poblados predominen las interacciones humanas breves, formales, superficiales, segmentadas e instrumentales sobre las prolongadas, informales, amistosas y confiadas. Ello es así, por cuanto en el medio urbano se deben, necesariamente, entablar numerosas y rápidas relaciones sociales con conjuntos de personas que se renuevan constantemente y el ritmo de vida mismo torna imposible la cristalización de un conocimiento profundo y una comunicación afectiva con los demás. El otro es casi siempre un extraño, respecto del cual se dispone de un tiempo muy escaso como para conversar e intimar.

Más aún, en diversas ocasiones los otros pasan a ser competidores a desplazar, pues pretenden alcanzar los mismos objetos o servicios: un microbús, una entrada al cine, una oportunidad de empleo. De esta forma el otro en el contexto urbano se le percibe como un ser anónimo que a lo menos dificulta aquello que se desea, o bien, en otras oportunidades, deviene en un extraño potencialmente peligroso al que se le mira con desconfianza, en tanto no demuestre que sus intenciones son socialmente irreprochables.

Inmerso en este ambiente social masificado y tensionante, ¿qué podría esperarse de la familia y del hogar?

Por lo general, el hombre urbano busca en el hogar un remanso que lo aleje $y$ proteja de las aglomeraciones, y el bullicio a que se ha visto expuesto durante el día; una especie de refugio en que pueda estar en paz, ser él mismo, sacándose las "máscaras" que ha debido colocarse para desempeñar diversos roles laborales. De alguna manera busca "meterse en su casa" y liberarse de la sobre-estimulación a que ha sido sometido.

Sin embargo, como se sabe, estas expectativas no siempre se cumplen. Debido fundamentalmente a factores económicos - alto costo del suelo urbano y de las viviendas- en las metrópolis se ha apreciado la tendencia a construir unidades cada vez más pequeñas, de manera de palear los déficit habitacionales. Este hecho 
es más apreciable aún en los países no desarrollados, en los cuales con una menor disponibilidad presupuestaria se intenta satisfacer una creciente necesidad por viviendas, la que afecta, de preferencia, a los segmentos sociales que perciben más bajos niveles de ingreso.

El tamaño reducido de los espacios suele impedir que las familias logren la privacidad, en términos que permita a sus componentes entablar relaciones sociales sin ser molestados por los demás. Las dimensiones mezquinas muchas veces impide que los niños y adolescentes dispongan de un territorio interior "propio" en donde puedan jugar, entretenerse, escuchar música de su preferencia, por ejemplo, o simplemente conversar con intimidad con amigos, sin perturbar o ser perturbados por los otros miembros de la familia. Algo similar suele suceder con los adultos; al jefe de familia le es muchas veces difícil tener un lugar en que pueda descansar tranquilo o compartir confidencias con su esposa sin ser escuchado; o ésta desarrollar actividades como dueña de casa con la tranquilidad necesaria.

Además, como resultado de la insuficiencia de espacios interiores éstos suelen no estar bien delimitados funcionalmente, entorpeciendo el quehacer cotidiano y provocando conflictos entre los componentes de la familia. En diversas oportunidades ha sido posible constatar que baños de servicios no son utilizados para su función, sino para guardar utensilios del hogar que no pueden ser ubicados en una despensa, limitando así los espacios destinados a la higiene; o bien el estar -ámbito dispuesto para recibir o a permitir la comunicación familiar- debe ser habilitado para cumplir paralelamente otras funciones, ubicando allí mobiliario que no tienen cabida en otros recintos de las viviendas.

Como es de suponer, la estrechez de las dimensiones de las habitaciones conduce a que las familias vivan en un estado de hacinamiento, a percibir que los demás están más próximos de aquello que sería deseable o a sentirse innecesariamente "controlado", en circunstancias en que se quiere comunicar sentimientos con sólo algunos de los componentes del grupo familiar. En estos casos, los miembros mismos de la familia parecen molestar -aunque no lo pretendan por cierto-ocasionando reacciones defensivas de la intimidad perturbada o interrumpida, e incluso agresivas hacia los "intrusos". Estos mecanismos suelen ser más utilizados por los adolescentes, quienes son particularmente sensibles a los controles y desean tener libertad y autonomía en su vida hogareña.

Por otra parte, las áreas residenciales urbanas tienden a densificarse, siendo cada vez más común la edificación en altura - bloques de departamentos unifamiliares-o la construcción de conjuntos habitacionales de uno o dos pisos conocidos como "villas" o "poblaciones". Por la configuración de los espacios, en ambas situaciones las familias se ven prácticamente obligadas a relacionarse con sus vecinos, a convivir con ellos, por cuanto además estos vecindarios disponen de servicios comunes para todos ellos, tales como equipamiento comercial para el 
abastecimiento cotidiano y espacios semipúblicos -áreas verdes, pasajes, etc.que deben, de alguna manera, compartirse entre todos los residentes.

El problema surge cuando no existe armonía entre vecinos que se encuentran tan próximos, de manera que es casi imposible evitar encontrarse en el hábitat residencial. Investigaciones realizadas en distintas poblaciones populares de Santiago en el Departamento de Sociología han revelado una gran variedad de situaciones. En efecto, en algunas villas o poblaciones prevalece una alta sociabilidad entre los vecinos, siendo frecuente la ayuda mutua, "contándose con ellos" para resolver problemas; en otros, en cambio, los residentes de estos hábitat pobres han manifestado una opinión negativa, aduciéndose que "no se puede pedir ayuda a un vecino, porque siempre se lo saca en cara" o que "los amigos es mejor tenerlos lejos del vecindario".

A pesar que en los conjuntos residenciales pobres la condición económica de sus residentes es relativamente similar, es posible detectar en su interior ciertos indicios de micro-estratificación social. Así, quienes han mejorado sus niveles de ingreso tienden a demostrar a sus vecinos su progreso, cambiando el material de las fachadas de las viviendas, colocando rejas de fierro en las casas con antejardin y/o modificando las puerta y ventanas. Por ello, a pesar que estos conjuntos residenciales tienen un mismo estado inicial desde el punto de vista arquitectónico al momento de ser entregados a sus usuarios, muy pronto sus residentes le introducen modificaciones ostensibles que le permitan una identificación social favorable, con lo cual la uniformidad constructiva de las poblaciones da lugar, con el transcurso del tiempo, a una creciente heterogeneidad físico-social.

Acaso como consecuencia de las menguadas dimensiones de las viviendas y del nivel de hacinamiento, es frecuente que en estos hábitat residenciales los niños, adolescentes y jóvenes permanezcan muchas horas en las calles y pasajes, a veces lejos del control de los padres o de personas adultas. Con los vecinos conforman grupos de juegos y "patotas" con los cuales se apropian de lugares del sector. Así los espacios públicos residenciales devienen en verdaderos ámbitos socializadores, ya que los amigos del vecindario transmiten valores, normas y actitudes que pautan el comportamiento de la juventud radicada en el sector residencial. En el interior de estos grupos de iguales - desde el punto de vista cronológico y especialmente de desarrollo socioemocional- los infantes y adolescentes encuentran acogida, reconocimiento y protección, siendo por tanto muy valorados por ellos. En este entorno se sienten liberados de las imposiciones normativas del "mundo adulto", pudiendo desarrollar actividades que, de efectuarlas en el interior de sus casas, merecerían una severa reprobación.

Lo anterior apunta a una de las peculiaridades que presentan muchos jóvenes residentes en áreas residenciales de bajos ingresos: la confusión valorativa que conduce a una imprevisibilidad en su comportamiento. Dicha confusión deriva, en gran parte, del hecho que se ven expuestos a la influencia simultánea de varios 
agentes de socialización: la familia - cuya fuerza y eficacia en el proceso socializador va a depender del clima armónico y afectivo de las comunicaciones entre sus componentes-; la escuela - que otrora tenía una influencia más decisiva en la formación de los adolescentes, tal vez por cuanto éstos permanecían la mayor parte del día en las unidades educativas en contacto con sus maestros- $y$, de una manera cada vez más importante, la televisión, que muestra modelos de comportamiento aparentemente dignos de imitación.

Como se comprenderá, es muy difícil que los mensajes emitidos por la familia, la escuela, la televisión y los grupos de pares sean coherentes entre sí; por otra parte dado el nivel de inmadurez de los niños y adolescentes, a éstos no les es posible conformar un marco valorativo organizado u optar de manera deliberada y crítica por pautas conductuales y actitudes consideradas como socialmente positivas. Si se encuentran sin apoyo afectivo de partes de personas con autoridad, la natural desorientación juvenil será mayor y lo probable será que sean más receptivos a los estándares de sus grupos de amigos del barrio, con los cuales mantienen contactos más vitales e intimos. De esta manera, las normas subculturales de la "patota" o de la "pandilla" se impondrán y serán más eficaces que las transmitidas por los padres o los profesores, convirtiendo a los vecinos del barrio en la fuente principal de las que los niños y adolescentes adquieren sus concepciones sobre el bien y el mal.

Por cierto que no siempre el hábitat residencial urbano representa un ámbito socializador negativo; lo será hipotéticamente, en cuanto la familia y la escuela no cumplan su función transmisora de la herencia cultural y los adolescentes no encuentren modelos adultos atractivos; sólo entonces buscarán la identidad social que el apoyo de los grupos callejeros y las recompensas emocionales que los agentes de socialización formal no les entregan. Si esto ocurre a temprana edad, ya jóvenes habrán cortado su relación con el "mundo institucionalizado", abriéndose casi espontáneamente la posibilidad de conformar y aprender de los demás sus propios códigos de conducta, que eventualmente pueden definir de forma favorable actividades trasgresoras a una moralidad y legalidad vigente.

La opción por los medios ilegales para la obtención de objetos y fines socialmente deseados es posible que ocurra mientras mayor sea la desorientación valórica de los muchachos. Desprovistos de un control social mínimo, algunos procurarán alcanzarlo a través de la violencia, con lo cual las pandillas se tornarán en bandas agresoras que controlarán celosamente espacios públicos residenciales urbanos; otros renunciarán al logro de los fines y buscarán evadirse en las drogas o el alcohol.

Para finalizar, retomando el punto de partida de este artículo, habría que señalar que los cambios que han experimentado históricamente los hábitat humanos se han visto fuertemente influidos por las transformaciones que han tenido lugar en la civilización misma. Las innovaciones tecnológicas, la aparición de 
nuevas formas de relaciones económicas y la rápida emergencia de heterogéneos conglomerados sociales que se concentran en las grandes metrópolis conducen a plantear, de cara al futuro, algunas interrogantes sobre las características que tendrán éstas $y$ las adaptaciones que necesariamente deberá experimentar la familia.

¿Podrán las ciudades continuar aumentando en población y densidad y extensión indefinidamente? ¿Tendrán éstas la suficiente plasticidad para acoger y asimilar la avalancha de nuevas ideas y productos sin llegar a un colapso? ¿Encontrará el hombre posibilidades de lograr una vida más plena en el orden material y especialmente en lo espiritual o deberá construir otro tipo de hábitat para lograr su felicidad? ¿La familia misma, continuará siendo la institución social básica, o su funcionamiento sufrirá tales transformaciones en las próximas generaciones que la harán irreconocibles para la actual?

Si bien es cierto muchos pensadores han intentado responder de alguna manera estas interrogantes, en último término el destino del hombre y de la civilización parece inescrutable a largo plazo. Dejaremos a cada lector este hermoso, vital y acaso inquietante desafío. 